\title{
Letter to "the Prevalence of Incidental Thyroid Carcinoma in Patients Who Underwent Thyroidectomy for Multinodular Goiter"
}

\author{
Mesut Tez ${ }^{1}$
}

Received: 11 May 2017 / Accepted: 30 July 2017 / Published online: 4 August 2017

(C) Association of Surgeons of India 2017

\section{Dear Editor,}

I read with great interest the article titled "The Prevalence of Incidental Thyroid Carcinoma in Patients Who Underwent Thyroidectomy for Multinodular Goiter" by Terzioğlu et al. [1]. However, there are certain criticisms I should point out. Firstly, in the abstract of the article, there are missing data denoted with question marks.

Secondly, in Turkey, including Ankara Numune Training and Research Hospital, total thyroidectomy is the preferred surgical procedure in multinodular goiter patients $[2,3]$, but bilateral thyroidectomy rate was $32 \%$ in the presented article [1]. How do the authors explain this high bilateral subtotal thyroidectomy rate?

Thus, I cannot quite perceive the content and consistency of the data presented in this particular article.

\section{Compliance with Ethical Standards}

Conflict of Interest There is no conflict of interest to declare.

\section{References}

1. Terzioğlu SG, Özgür Kılıç M, Sapmaz A, Karaca AS (2017) The prevalence of incidental thyroid carcinoma in patients who underwent thyroidectomy for multinodular goiter. Indian J Surg 1-4. doi: 10.1007/s12262-017-1611-5

2. Yoldas T, Makay O, Icoz G, Kose T, Gezer G, Kismali E, Tamsel S, Ozbek S, Y1lmaz M, Akyildiz M (2015) Should subtotal thyroidectomy be abandoned in multinodular goiter patients from endemic regions requiring surgery? Int Surg 100(1):9-14

3. Dogan L, Karaman N, Yilmaz KB, Ozaslan C, Atalay C (2011) Total thyroidectomy for the surgical treatment of multinodular goiter. Surg Today 41(3):323-327
Mesut Tez

mesuttez@yahoo.com

Ankara Numune Hospital Department of General Surgery, Talatpaşa bulvarı no: 5, 06100 Samanpazarı, Ankara, Turkey 